\title{
Osteonecrosis Femoral Head Treatment by Core Decompression and ILIAC CREST-TFL Muscle Pedicle Grafting
}

\author{
Sudhir Babhulkar \\ Indira Gandhi Medical College, Nagpur, \\ Sushrut Hosp, Research Centre \& PGI, Nagpur, \\ India
}

\section{Introduction}

Osteonecrosis of femoral head is a painful disabling condition seen in association with many disorders like corticosteroids consumption, alcohol abuse, haemoglobinopathy (sickle cell disease, coagulopathies), certain renal, hepatic and skin disorders commonly affecting young patients ranging from $20-40$ years. ${ }^{1-3}$ It is now recognized as a major musculo-skeletal problem mostly affecting the young people in their productive years of life. It is often characterized by relentless progression despite treatment, resulting in to subchondral fracture, collapse and painful arthrosis. ${ }^{4}$ Hence it is essential to diagnose and treat the patients of osteonecrosis early to prevent any further disintegration and collapse of femoral head. Advanced osteonecrosis with secondary osteoarthritis is reported in 5\% to $18 \%$ of total patients undergoing total hip replacement in the US.4-7 Aim of the treatment in osteonecrosis is to reduce the intraosseous pressure and to perform the head-preserving procedure, which will cause early revascularization of ischemic head. Various types of muscle pedicle grafting after core decompression are indicated early in the disease, depending upon the stage of the disease and have shown excellent results in revascularization of femoral head and prevention of collapse.

Once diagnosed it is desirable to subject the patient to early surgical intervention. Rationale for the treatment of osteonecrosis of femoral head requires a lot of consideration. Of prime importance is the age of patients. Whether both hips are affected, etiology of the associated diseases, demands and requirement of the patients, and the stage of the disease when the patient presents for treatment are equally important. The treatment is planned according to ARCO's classification ${ }^{8} \&$ Steinberg staging 9 . Only core decompression may relieve the pain but it does not achieve revascularization of femoral head. Hence core decompression should always be supplemented by one of the procedures of bone grafting. To achieve early vascularisation, vascular pedicle grafting using deep circumflex iliac vessel with iliac crest is a very useful, but preoperative femoral angiography is mandatory to confirm the presence of deep circumflex iliac artery pedicle ${ }^{10}$. This procedure is technically demanding, tedious and time consuming and may not be feasible bilaterally in one sitting. However Muscle pedicle graft using tensor fascia lata graft is very easy and is commonly performed 
whenever both hips need simultaneous surgery in one sitting. In the past, muscle pedicle graft using quadratus femoris (Meyer's procedure) ${ }^{11}$ was propagated in the treatment of osteonecrosis, but it did not achieve satisfactory early revascularization and came in disrepute since the results were not encouraging. Dr DP Baksi ${ }^{12}$ reported treatment of osteonecrosis by multiple drilling and muscle pedicle grafting by use of TFL graft with relief of pain and improvement in the hip movements. Though vascularised pedicle graft by using part of iliac crest with deep circumflex iliac vessels is more advantageous since high percentage of marrow and osteogenic cells survive within a living graft, it is difficult to perform this surgery on both hips in one sitting. As per our Institutional philosophy we prefer to operate both hips in the same sitting since it reduces the hospital stay, the cost of drugs and many cases patient may not turn up for surgery on the opposite hip, especially the poor compliance group of patients. Hence use of Muscle pedicle graft of tensor fascia lata along with iliac crest after core decompression is commonly advocated when bilateral hips are involved and surgery is recommended early in single sitting.

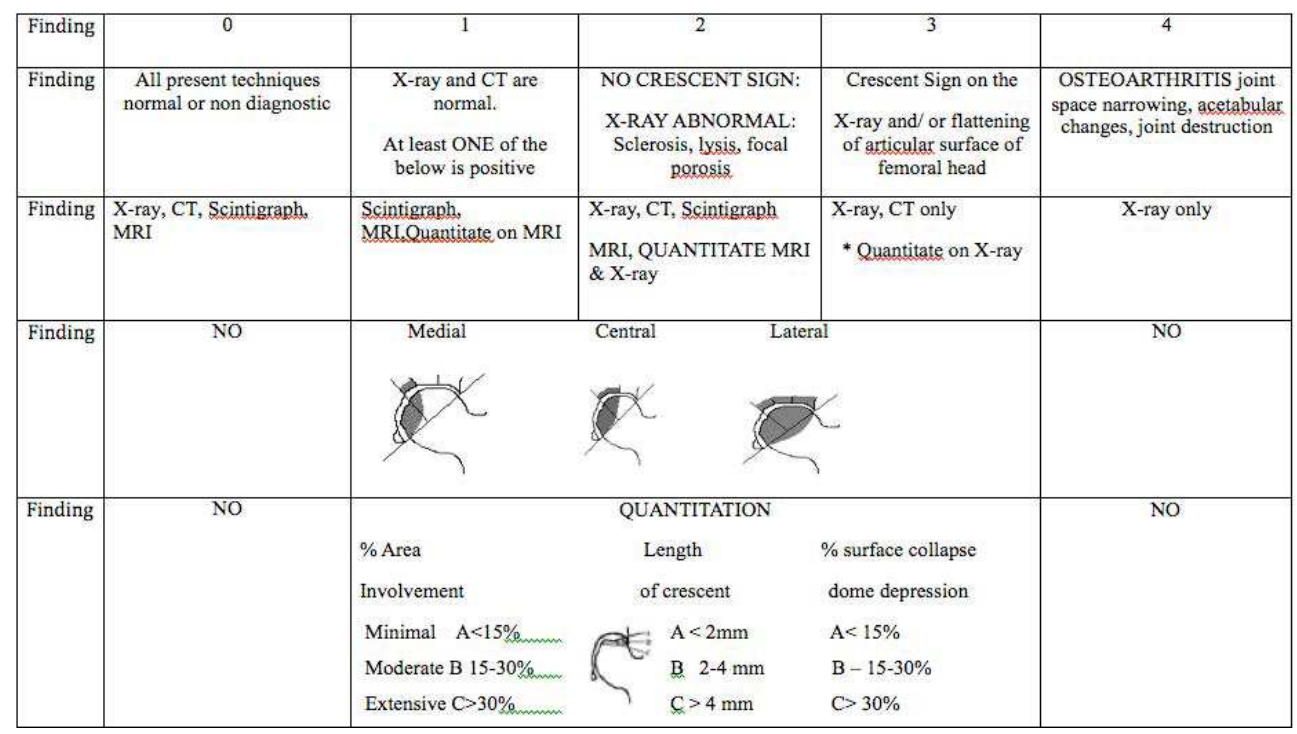

Table 1. ARCO Classification

The natural history of osteonecrosis of femoral head, before the development of crescent sign or before the collapse of the femoral head, has never been well defined. The possibility of progression to collapse is thought to increase after the development of an abnormality that can be seen on plainradiograph and the course of collapse may be highly variable and unknown ${ }^{7}$. It is generally agreed that symptomatic radiographically abnormal hip will progress to collapse of the femoral head when treated nonoperatively 7 .To avoid these complications and to avoid early replacement arthroplasty in young patients many operative procedures to salvage the femoral head are in vogue. Head preserving operation of core decompression and various types of bone grafting certainly gave excellent results in early stage of osteonecrosis. Despite the many reports on the utility of various operative procedures no single method has uniformly demonstrated the arrest of the disease or prevention of collapse of the femoral head 
effectively. Core decompression only gave good clinical results initially( Ficat \& Arlet) ${ }^{13,14}$, but the long term results were poor. ${ }^{11}$ The use of nonvascularised tibial (Phemister) or fibular bone graft (Boettcher \& Bonfiglio) ${ }^{15}$ is useful only in the early stages but in later stages, the results were very poor. Subarticular curettage and cancellous bone grafting failed to relieve pain and prevent progressive collapse of the femoral head. ${ }^{16,17}$ Meyers ${ }^{11}$ reported use of fresh cancellous graft combined with Quadratus femoris muscle pedicle graft which gave good results in stage I \& II, but was unsatisfactory in stage III \& IV. Though pain and deformity improved initially, vascularisation of femoral head was poor.

The vascularized fibular grafting is associated with better clinical and radiographic results than is nonvascularized fibular grafting in precollapse hips ${ }^{7}$. However, the successful use of free vascularized bone grafts requires a meticulous process of procuring the vascular fibula with microanastomosis to the recipient site. The microsurgical procedures require specialized training equipment and expertise.

The TFL muscle pedicle graft by using part of iliac crest described in this article is easy to perform and does not require any special equipment or technique, and still has the advantages of increased vascularity like vascularised bone graft (Fig 1A-1H). We analyzed and report a series of patients of osteonecrosis of femoral head treated by core decompression and TFL muscle pedicle graft of part of iliac crest.
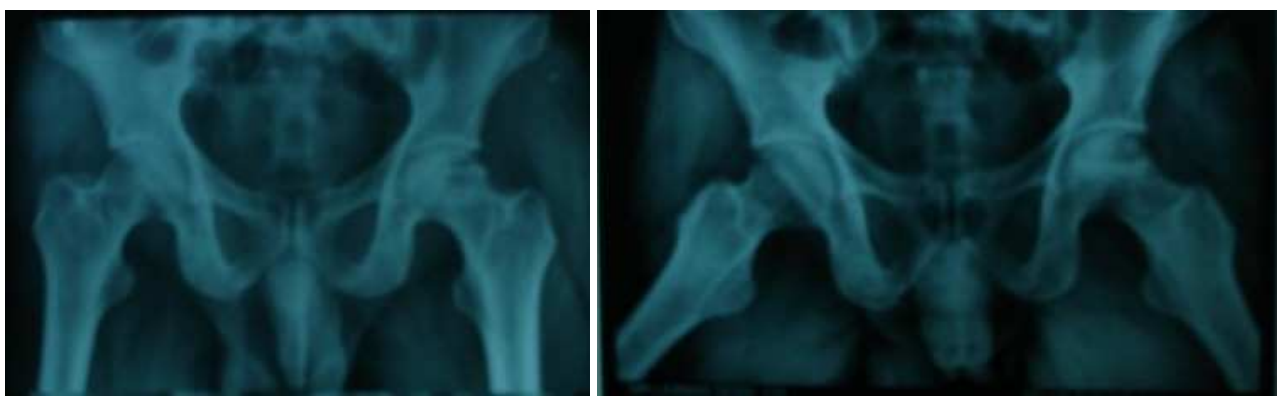

LD - 52 years male Steroid Induced ON femoral head left side

Fig. 1. 1A, 1B- Pre op X-ray 52 year's male Steroid Induced ON femoral head left side
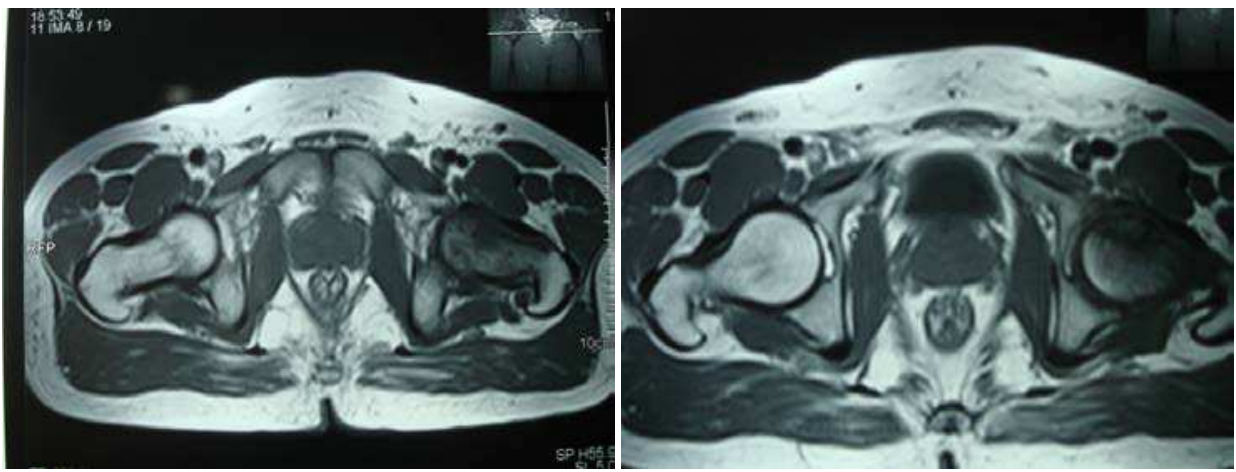

Fig. 1. 1C, 1D - Pre op MRI showing classical changes of ON left side 

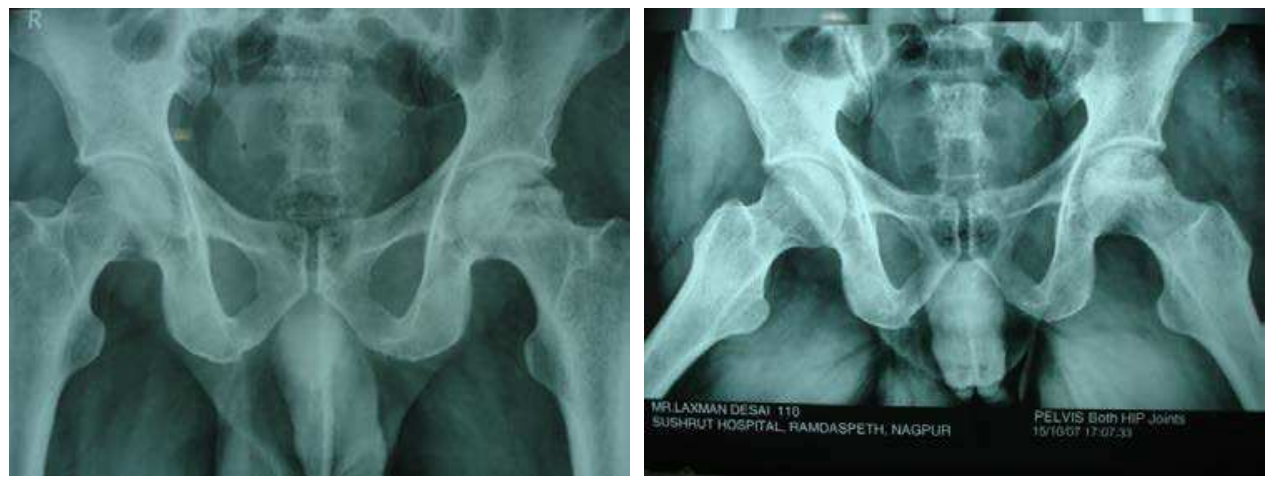

Fig. 1. 1E, 1F - Immediate Post op X ray after CD \& TFL draft
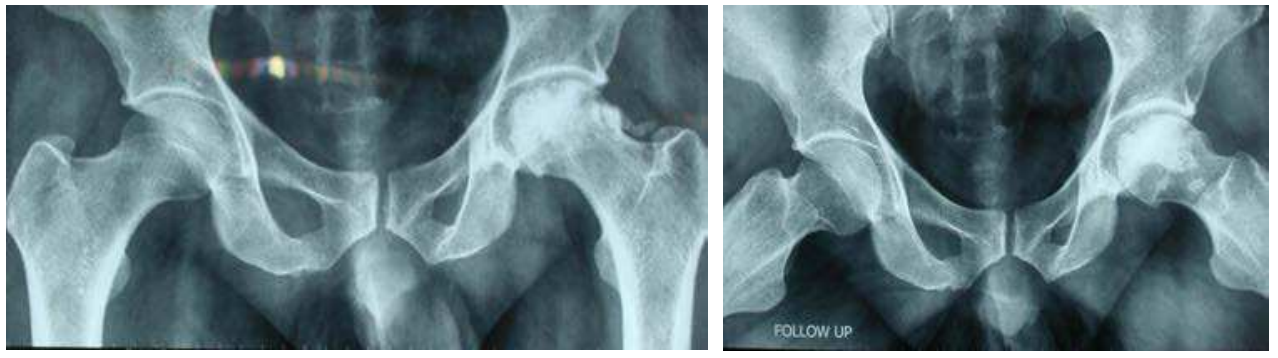

Fig. 1. 1G, 1H - Post op 3 years follow up X ray after CD \& TFL draft showing good revascularization and restoration of contour of femoral head left side

\section{Material \& methods}

This article reports the study of 68 patients of osteonecrosis femoral head, affecting 92 femoral heads in stage II \& III, wherein 90 hips were treated with core decompression and Iliac crest-TFL muscle pedicle grafting by using part of iliac crest with Tensor Fascia lata (TFL) pedicle in a duration of 16 years, from Jan.95 to Dec.2010 with a minimum follow up for three years. All patients were young 16-52 years of age with a mean age of 30 years.

Forty four patients had unilateral affection where as twenty four patients had bilateral involvement, but on twenty two occasions bilateral TFL grafting was done in one sitting, whereas two patients in bilateral group were operated by TFL muscle pedicle graft on one side \& free fibular grafting on the opposite side in single sitting (Fig 2A-2H, Fig 3A-3G). Thus TFL Grafting procedure was performed on total 90 hips in 68 patients. At our Institute many patients of Sickle cell disease with osteonecrosis are studied and treated, where the procedure of vascular pedicle grafting is not performed on any patient, because of the possibility of high prevalence of thrombosis in the vascular pedicle in this disease. Similarly in patients with bilateral involvement, surgery of TFL grafting in one sitting is preferred to vascular pedicle grafting, mainly because of the long time required for vascular pedicle procedure. Amongst 68 patients, 28 patients (42\%) were following Alcohol abuse, 21 patients $(30 \%)$ were following consumption of corticosteroids \& 19 patients had sickle cell haemoglobinopathy $(28 \%)$. The demography of patients is shown in the Chart 2 . Amongst 
24 Bilateral hips, 17 patients had stage III on one side \& stage II on other side. Wherein 7 patients had stage III in both hips.
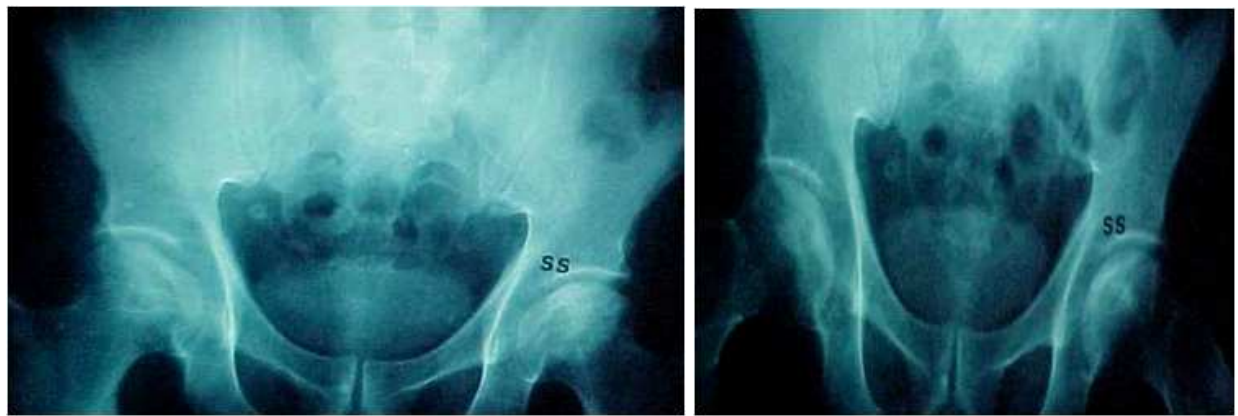

SCS

Fig. 2. 2A, 2B - Pre op X-ray 50 years male Steroid Induced ON femoral head both sides

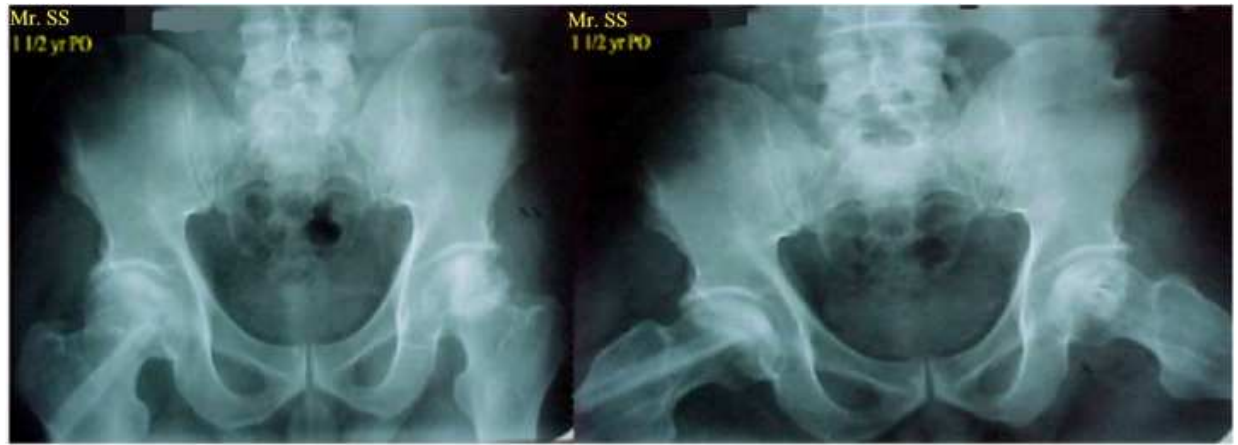

Fig. 2. 2C, 2D - Post op 1.5 years follow up X ray after CD \& TFL graft on left side \& free fibular graft on right side showing good revascularization and restoration of contour of femoral head

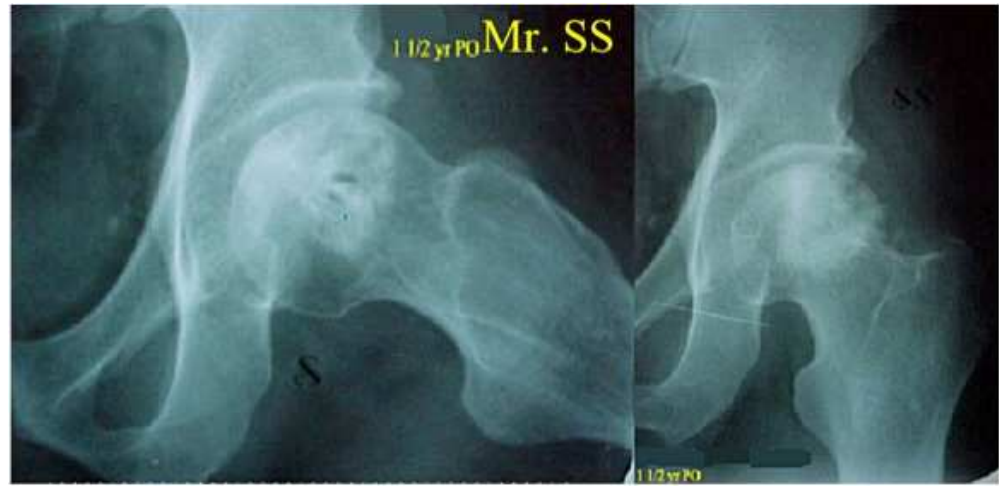

Fig. 2. $2 \mathrm{E}, 2 \mathrm{~F}-1.5$ years $\mathrm{PO}$ showing good revascularization and restoration of contour of femoral head on left side after CD \& TFL graft 

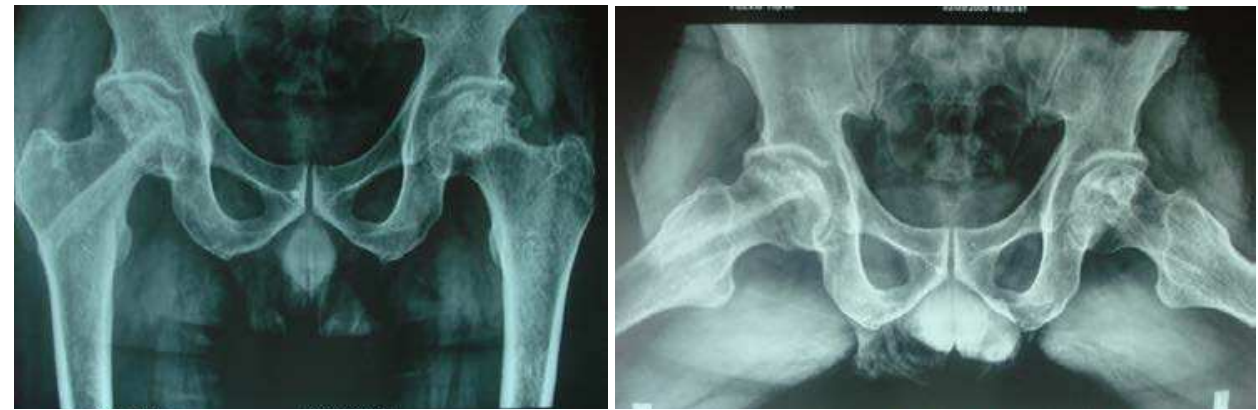

Fig. 2. 2G, 2H - 9 years PO showing good revascularization and restoration of contour of femoral head on left side after CD \& TFL graft with good hip joint space.

\begin{tabular}{|c|c|c|c|c|c|c|c|}
\hline \multirow{2}{*}{$\begin{array}{l}\text { Stage of } \\
\text { Disease }\end{array}$} & \multirow{2}{*}{ Number of Hips } & \multirow{2}{*}{$\begin{array}{l}\text { Male } \\
\text { Hips }\end{array}$} & \multirow{2}{*}{$\begin{array}{l}\text { Female } \\
\text { Hips }\end{array}$} & \multicolumn{4}{|c|}{ Age of the patient } \\
\hline & & & & $16-20$ & $21-30$ & $31-40$ & 41 \& Above \\
\hline \begin{tabular}{|l} 
Stage II \\
A \\
B \\
C \\
\end{tabular} & $\begin{array}{l}33 \\
- \\
15 \\
18 \\
\end{array}$ & 20 & 13 & 2 & 11 & 16 & 4 \\
\hline \begin{tabular}{|l} 
Stage III \\
A \\
B \\
C \\
\end{tabular} & \begin{tabular}{|l|}
57 \\
6 \\
36 \\
15 \\
\end{tabular} & 36 & 21 & 4 & 18 & 22 & 13 \\
\hline
\end{tabular}

Table 2. Showing demography of patients affecting 90 Hips operated by TFL grafting showing stages, age \& Sex.

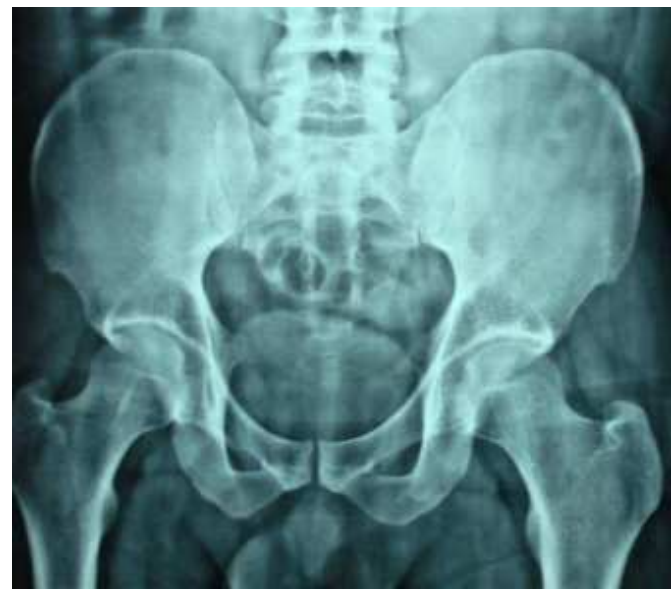

RC 28 year male Alcohol Induced

Fig. 3. 3A - X ray showing Alcohol induced ON both sides in 31 years male 


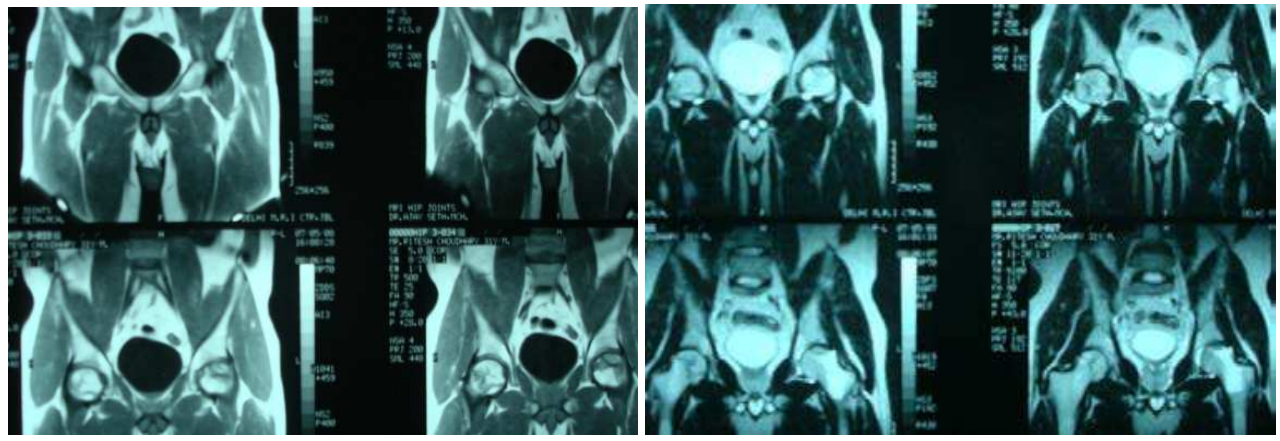

Fig. 3. 3B, 3C - MRI showing bilateral ON femoral heads
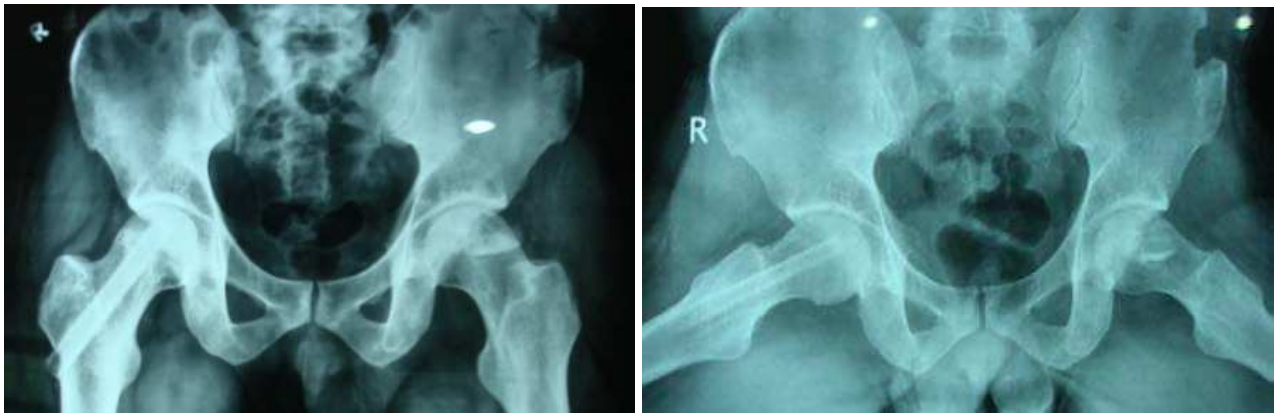

Fig. 3. 3D, 3E - 12 weeks PO after CD \& TFL graft left side \& free fibular graft right side
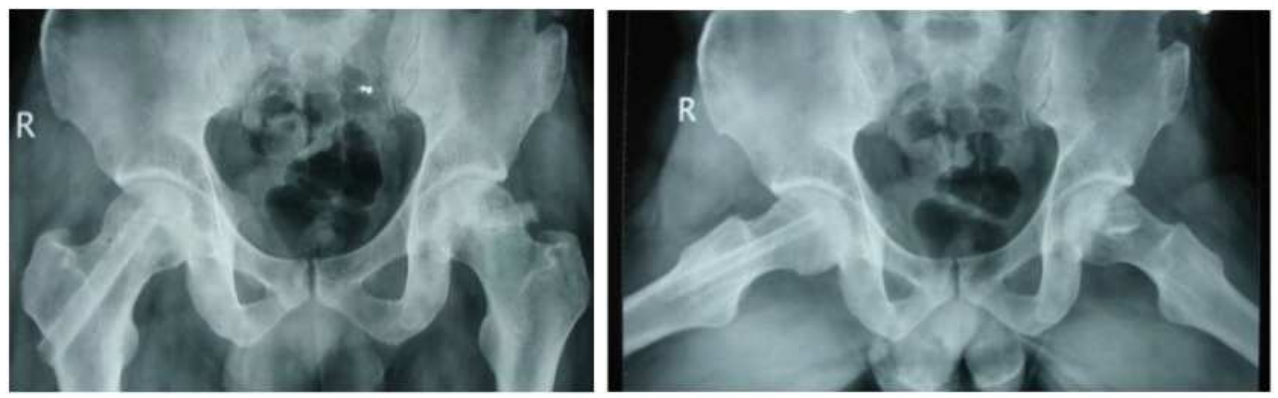

Fig. 3. 3F, 3G - 1 year PO after CD \& TFL graft left side \& free fibular graft right side showing good consolidation of TFL graft left side with restoration of normal femoral head contour 


\subsection{Operative technique}

Patient after spinal anesthesia, is put in supine position with the sandbag underneath the gluteal region on the operative side. A curvilinear incision is taken on lateral side of hip extending from the iliac crest about $5 \mathrm{~cm}$ posterior to Anterior superior iliac spine and to the greater trochanter and extending downwards about $2 \mathrm{~cm}$ below the base of greater trochanter in the subtrochanteric region. The iliac crest should be exposed, freed from inner lip by erasing three abdominal muscles till you just reach about $2 \mathrm{~cm}$. Similarly the iliac crest with attached tensor fascia lata on external surface should be exposed. The cleavage between Sartorius and tensor fascia lata is identified. An incision is made between anterior \& middle fibers of TFL and clearly 2 - $3 \mathrm{~cm}$ width of TFL middle fibers are separated up to the iliac crest. With pneumatic saw osteotomy of iliac crest is done superiorly, and about 2 $3 \mathrm{~cm}$ distally and medially with isolation of TFL graft externally. This isolated iliac crest graft with TFL pedicle is best done by subperiosteal separation of muscles on either side of lip of the ilium without disturbing the vascular supply. The desired size of TFL with full width of iliac crest is raised \& retracted downwards with attached fibers of TFL. The TFL muscle pedicle graft just prepared gets its vascular supply from the superior gluteal artery and ascending branch of lateral circumflex femoral artery. The reflected pedicle of TFL with fibers of gluteus minimus muscle is erased from the outer surface of ilium and is retracted downwards and brought down up to the anterior capsule of the involved hip joint. The hip capsule is opened with $\mathrm{T}$ shaped incision. The anterior capsule and thickened synovium is excised. The ischemic necrotic segment is exposed and examined for its deformation \& change in the contour. A small window is made anteriorly at the junction of articular surface of the femoral head and anterior surface of the neck of the femur by pneumatic drill. Under image intensifier through this window, serial reaming is done in the ischemic segment of the femoral head right up to the subchondral region in all the directions. Care is taken not to perforate the articular surface. Subsequently the entire necrotic tissue is removed by curette which creates a big void in the head of the femur usually in the upper quadrant of the femoral head, wherein inferior quadrant is usually not disturbed. With the special instrument \& punch-impactor the deformed femoral head with articular cartilage is raised superiorly to match its original shape under IITV in all the direction. The created void is partially filled and packed with little cancellous bone removed from the iliac crest after performing the osteotomy. Subsequently the retracted \& raised pedicle of TFL with iliac crest is prepared nicely to repose through the window defect at the head neck junction. Two holes are made superiorly \& inferiorly in the femoral neck by of $2 \mathrm{~mm}$ drill bits. Similarly the two holes are prepared in the pedicle of iliac bone with TFL graft. Subsequently the TFL pedicle is impacted in to the head under image control right up to the subchondral region of femoral neck and the graft tied by No.1 Vickryl to the femoral neck. Additionally, the muscle belly is also stitched to the capsule inferiorly \& superiorly. The suction drain is kept at the hip \& iliac crest site and wound is closed in layers. In bilateral cases, the similar procedure is performed in the same sitting on the opposite side.

\subsection{Post operative protocol}

Postoperatively the limb-Hip is kept in 20-degree abduction and 30 degree flexion and 10 degree of internal rotation to avoid tension on the vascular pedicle. The patient is mobilized 
after 15 days in bed and after 4-6 weeks patient can be mobilized out of bed on non-weight bearing crutch walking if only one hip is operated. Whereas in bilateral cases, the patient is advised bed rest with mobilsation of hips after 4 weeks and weight bearing started after 10 weeks only. The patient is allowed partial weight bearing after 10 weeks and full weight bearing after 14-16 weeks.

\subsection{Follow-up}

Follow-up by clinical and radiological examination was done every 3 months for one year, every six months for next five years and then yearly follow up thereafter. Harris hip score system was used for assessment of the results. The follow up period varied from three to sixteen years. Post operatively Bone scan \& Digital subtraction arteriogram was done in twenty patients comprising of ten each in stage II \& III, at the end of 12 weeks, which showed hundred percent of patency and viability of the TFL muscle pedicle graft.

\subsection{Results}

The patients had good clinical improvement with relief from pain and improvement in the range of movements. The radiological improvement was judged by diminishen of density and attempt at revascularization as seen by healing of cystic changes, disappearance of crescent sign and restoration of normal trabecular pattern and shape of femoral head. Almost all patients had good relief from pain with good improvement in the range of movements. As per Harris Hip score results, there was improvement in the score of $>25$ points in $70 \%$ cases while in fifty \% had improvement in the score of more than 28 points in both the stages. The mean +SD improvement in Harris Hip score at 3 year's follow up was $27.6+6.4$. The difference in the preoperative and postoperative score across the whole sample was significant $(P<0.05)$

Stage II: Seventy percent of stage II hips completely improved without any deterioration and had complete relief from pain. No patient progressed to stage III postoperatively.

Stage III: About $20 \%$ patients of stage III had residual low intensity pain for about 30 weeks. About $30 \%$ patients had painless limp for 24-30 weeks with restriction of flexion beyond 100 Degrees. Eight percent patient (5 patients) progressed to further collapse, got deformed but without any progression to arthrosis. Out of this, in four percent patients (3 patients) surgery of total hip joint was advised.

\section{Discussion}

Need to treat ischemia of femoral head is becoming more common since many cases are detected in early stages in young patients. One must consider the possibility of osteonecrosis if individual has pain in the vicinity of hip, that had history of chronic alcoholism, corticosteroid consumption, associated disease like sickle cell disease, Gauchers, Gout etc ${ }^{18-}$ 21. Early diagnosis prior to the appearance of radiological changes is crucial in the treatment of ischemic necrosis. Its diagnosis is based on clinical examination and by bone scan, CT, and MRI, as osteonecrosis is the response to the vascular impairment of the bone marrow circulation. X-ray examination is of limited value in early stage, but has importance in staging since it helps in planning the treatment and the prognosis. The X-ray become 
positive late in the condition after the process of repair has started. The ischemic death of bony and marrow tissues occur in osteonecrosis. Different imaging modalities provide different information on the mineralized and non-mineralized component of the bone. Though bone scan is also important, MRI has dramatically improved the diagnosis of osteonecrosis, and in about $30-70 \%$ cases of femoral head osteonecrosis, the other hip is affected in due course of time ${ }^{18,22}$. Hence, it is necessary to rule out early involvement of the contralateral hip, which is asymptomatic by either bone scan or MRI. MRI is the most accurate imaging modality for the diagnosis of osteonecrosis of femoral head, especially in the early stages when there are only bone marrow changes ${ }^{23}$. Characteristic MRI signal alterations in the anterosuperior portion of the femoral head surrounded by a band of low signal intensity on T1- and T2-weighted images represent the diagnostic criteria of osteonecrosis ${ }^{25-27}$. The occurrence of a double-line sign on the T2-weighted image represents a pathognomonic sign, but its absence does not rule out the diagnosis of osteonecrosis. Marcus et al., Steinberg et al., Ficat and Arlet, and ARCOs classification28,7,8-29 are the various staging systems in vogue for diagnosis of osteonecrosis, but with inherent problems of low reliability. The Association Research Circulation Osseous (ARCO) has proposed a new international classification system including radiographs, computed tomography (CT), bone scans, and $\mathrm{MRI}^{8}$. This classification system incorporates the lesion size and the lesion location. Quantitation (\% area involvement of femoral head, length of crescent sign, \% surface collapse, and dome depression) and location of the lesion (medial, central or lateral) represent important prognostic factors. This ARCOs classification has been proposed as the preferred system for the future, which is used in this study.

Core decompression offers the opportunity to study histological changes of early bone ischemia. It also achieves reduction in the symptoms of pre-collapse stage of ischemic necrosis because of reduction of pressure in the compartment. Barring exceptional circumstances, there is hardly any role of conservative treatment of osteonecrosis of femoral head and surgery is rendered inevitable.

Steinberg et al. reported that progression occurred in $92 \%$ of 48 hips that had undergone nonoperative management ${ }^{30,31}$. While observing the patients with protected weight bearing, more than $85 \%$ patients had collapse of femoral head at 2 years when symptomatic hips with stage I and II were left untreated. Many studies have shown that nonoperative treatment yields poor results. The only condition for which the protected weight bearing might be effective is a type A lesion i.e. involvement of medial aspect of femoral head. No drugs have been useful and specific in the treatment of osteonecrosis, though recently the use of Alendronate has been advised. Once diagnosed, it is desirable to subject the patient to early surgical intervention. Rationale for the treatment of osteonecrosis of femoral head requires a lot of consideration. Prime consideration should be given to the age of the patient, whether both hips are affected, etiology of the associated diseases, functional demands of the patients, and the stage of the disease when the patient presents for treatment. Only core decompression may relieve the pain but is not useful for revascularization of femoral head; hence, core decompression should always be supplemented by one of the procedures of bone grafting. Core decompression is an effective treatment in the pre-radiological and precollapse stage of avascular necrosis of the femoral head, 18, 32, 33 especially if coupled with bone grafting. Jones analyzed nine studies and showed that in 218 of 369 patients (59\%), where core decompression was performed in the precollapse stage, failed to prevent the progressive collapse ${ }^{34-36}$. Steinberg et al ${ }^{19,30,31}$ concluded that core decompression provided 
more predictable pain relief and changed the indications for arthroplasty more consistently than conservative management. However, only core decompression should be avoided, and it must be coupled with bone grafting in the tract of core to avoid iatrogenic fractures.10, 37 Despite many reports on salvage procedure, no method has clearly demonstrated the arrest of disease before subchondral fracture or slow down of the progression of collapse of femoral head and arthrosis. The use of a nonvascularized bone graft, as originally described by Phemister, has had variable success in the treatment of osteonecrosis. Marcus et al ${ }^{28}$ reported satisfactory clinical results in seven out of eleven hips at the time of short-term follow up (range: 24 years). The other workers concluded that Phemister bone-grafting technique is not effective once collapse has occurred. Boettcher etal. ${ }^{15}$ reported success in 27 $(71 \%)$ of 38 hips 6 years after nonvascularized tibial strut grafting. However, a longer-term evaluation (performed at a mean of 14 years postoperatively) that included the original 38 hips in the study by Boettcher et al. found that only $16(29 \%)$ of 56 hips still had a good result. ${ }^{38}$ Once the crescent sign appears without collapse, it is desirable to couple the bone grafting procedure in addition to the core decompression, preferably vascular or muscle pedicle grafting, to achieve early revascularization. $39,10,12$.

Vascularized pedicle graft by using part of iliac crest with deep circumflex iliac vessels is more advantageous since high percentage of marrow and osteogenic cells survive within a living graft, which helps for early vascularization ${ }^{10,}$ 40-44. However, muscle pedicle graft using tensor fascia lata graft is very easy and is commonly performed whenever both hips need simultaneous surgery. Muscle pedicle graft using quadratus femoris (Meyers procedure) ${ }^{11}$ was also propagated in the treatment of osteonecrosis, but it did not achieve satisfactory early revascularization and went into disrepute since the results were not encouraging, though Meyers reported the success rate of $57 \%$ and Baksi ${ }^{12}$ reported $93 \%$ good results. Use of tensor fascia lata graft is commonly advocated when bilateral hips are involved and surgery is performed in the single sitting. The study by Plakseychuk et al ${ }^{42,43}$ on free vascular fibular grafting showed better clinical results and prevention of radiographic signs of progression and collapse of the femoral head more frequently than does nonvascularized fibular grafting. A marked difference with regard to signs of radiographic progression and collapse was noted between the $\mathrm{A}$ and $\mathrm{B}$ subgroups in the precollapse groups (Stages I, and II). The potential disadvantages of vascularized fibular grafting are a longer operation time, need of microvascular technique, leaves a longer operative scar, and is associated with more donor site morbidity such as ankle instability, toe-clawing, subtrochanteric fracture, and heterotopic ossification. To achieve early vascularization TFL muscle pedicle grafting along with iliac crest is very useful. This procedure is easy and is technically not demanding.

The TFL grafting provides a significant benefit for hips in Stages II and III. The rationale of this procedure (Fig 4A-4F, Fig 5A-5E) of TFL pedicle bone grafting is based on the following three points:

1. Decompression of the femoral head, which acts as compartment syndrome following increased intraosseous pressure and interrupts the circulation that is thought to contribute to the disease

2. Excision of the necrotic tissue, which inhibits revascularization of the head

3. Filling of the defect that is created after core and filled with TFL muscle pedicle with iliac crest, acts, an osteoinductive cancellous graft, which is viable and supports the subchondral surface and enhances the revascularization process. 

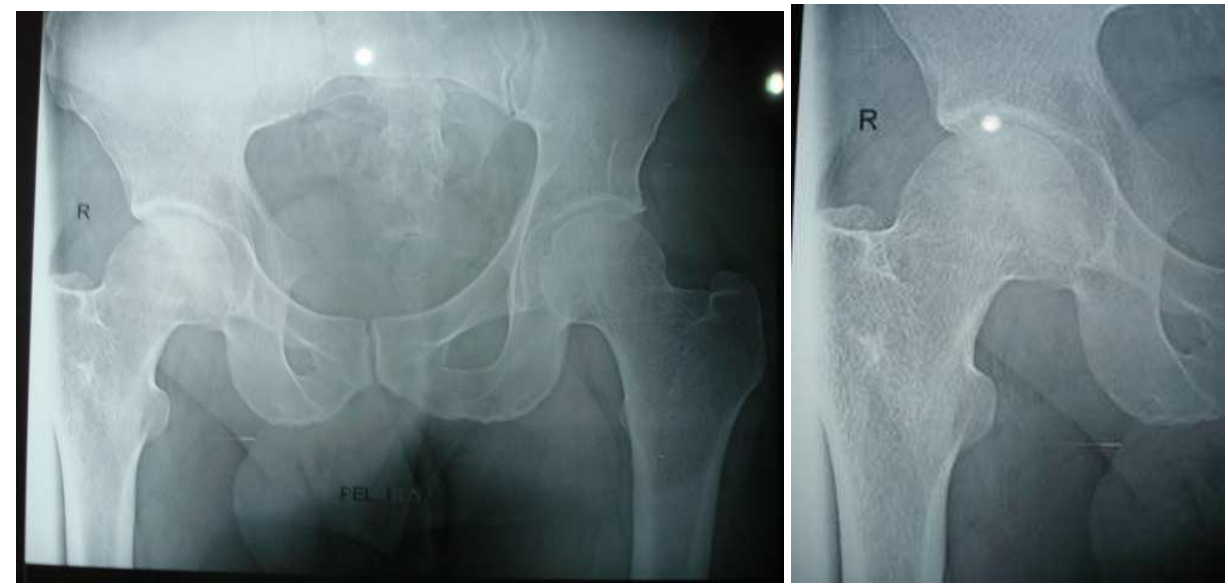

VS

Fig. 4. 4A, 4B - $\mathrm{X}$ ray showing Alcohol induced ON right side in 36 years male
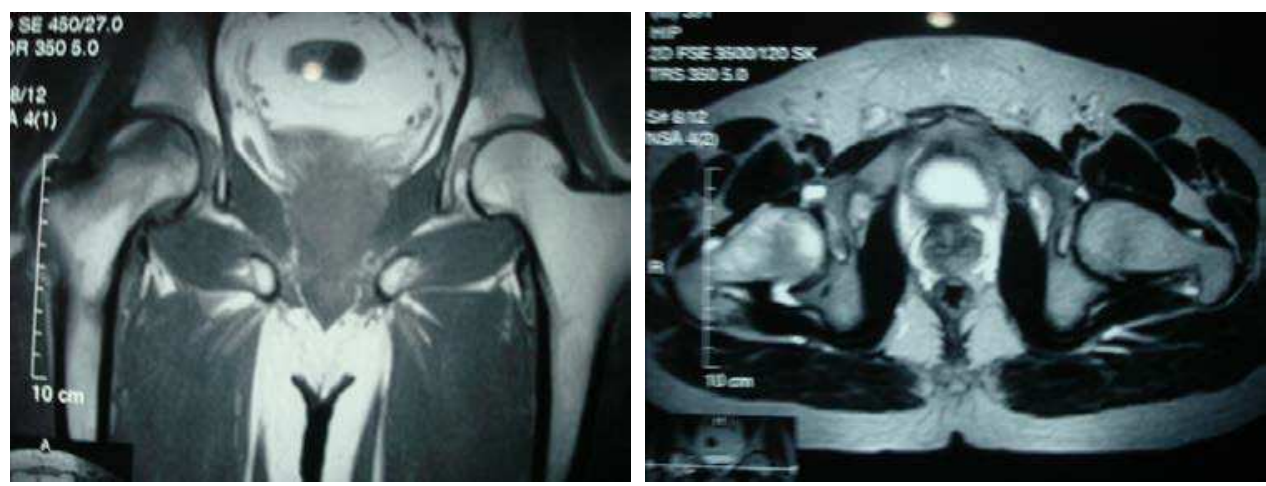

Fig. 4. 4C, 4D - MRI showing ON femoral head right side

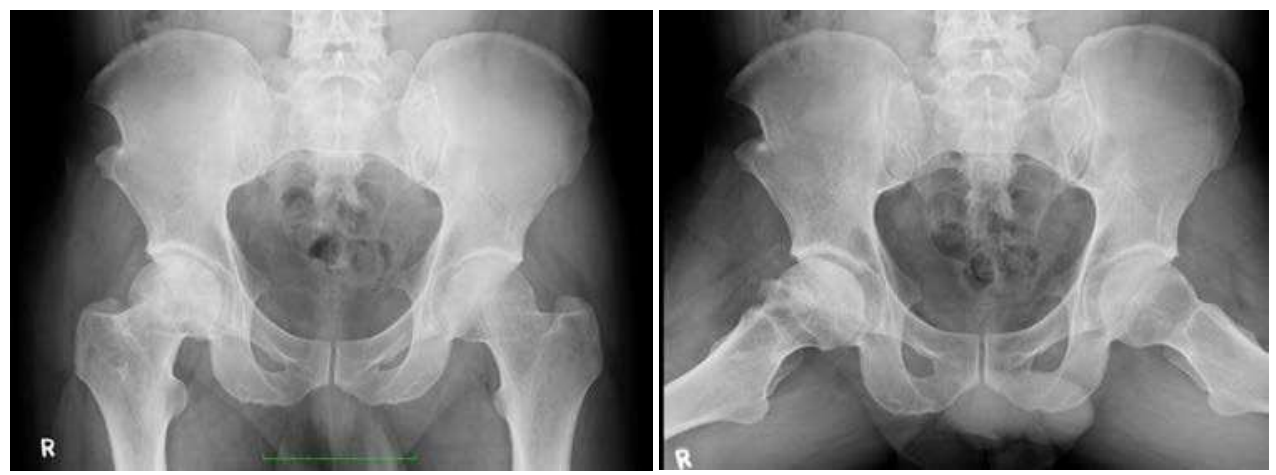

Fig. 4. $4 \mathrm{E}, 4 \mathrm{~F}-\mathrm{X}$ ray showing good incorporation of TFL graft maintenance of articular surface of femoral head at the end of 2 years follow up 


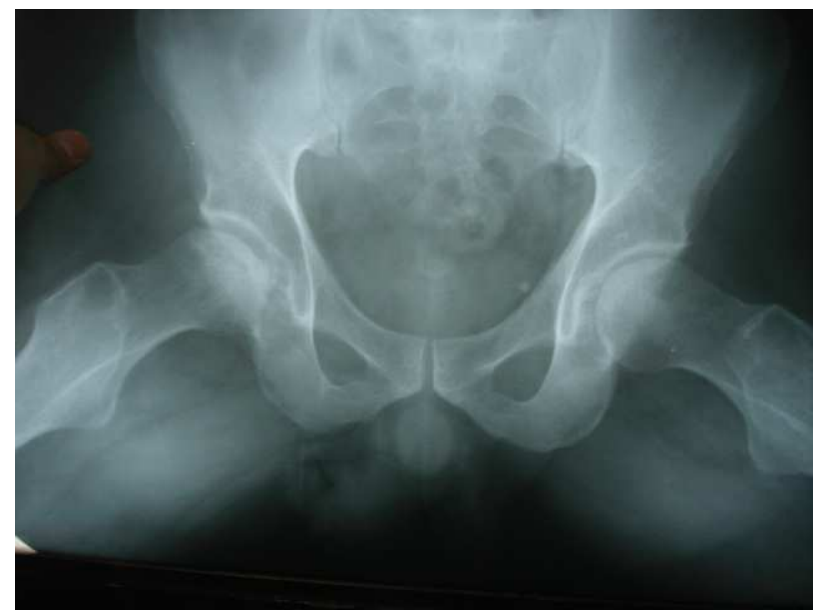

$\mathrm{TH}$

Fig. 5. 5A - X ray showing Alcohol induced ON both sides in 45 years male
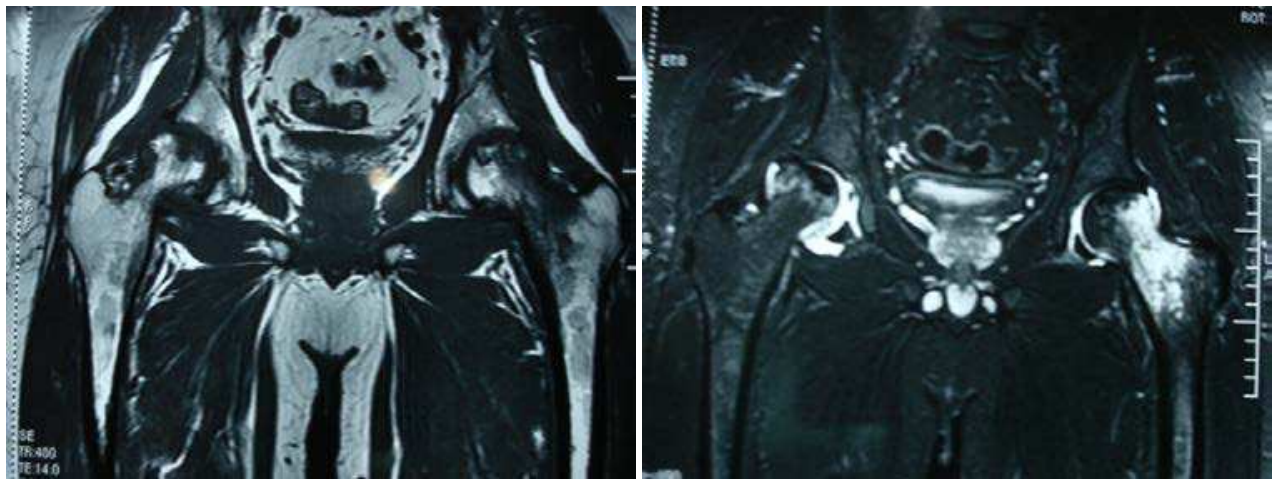

Fig. 5. 5B, 5C - MRI showing classical changes of AVN both femoral heads
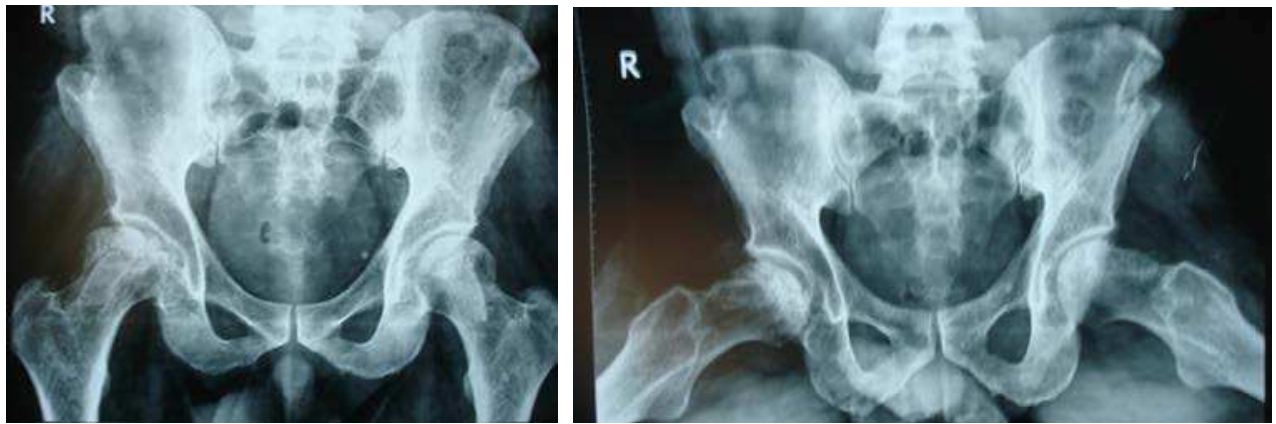

Fig. 5. 5D, 5E - 12 months PO CD \& TFL graft in one sitting showing good incorporation of graft and showing good restoration of articular surface 
It does not require advanced training of microsurgical technique nor any special equipment and can be performed by any average orthopaedic surgeon. Morbidity of the donor site is minimal and operative time required is comparable to total hip arthroplasty, and all problems and obstacles associated with vascularized fibular graft are avoided by this technique. Head-preserving operation of core decompression and TFL pedicle grafting certainly gives excellent results in stages II and III. The prognosis of stages II and III is fairly good, whereas in stage IV, it is not satisfactory since about $1 / 3$ of the stage IV group are likely to progress further and may require total hip joint replacement or resurfacing operations. Prosthetic replacement is frequently an unappealing option for patients who have osteonecrosis because many patients are young and the etiological factors associated with the disease are also associated with complications after total hip arthroplasty, hemiarthroplasty, and surface replacement. At our institute, many patients of sickle cell disease with osteonecrosis are studied and treated, by this procedure of TFL Muscle pedicle grafting. Out of 103 patients treated by Urbanaiak et al ${ }^{6}$ by free vascular fibular grafting, total hip replacement was performed in $34 \%$ cases in stages II and III within 5 years. There was survivorship and the probability of conversion within 5 years to THR rate of $11 \%$ in stage II and $23 \%$ survival for stage III. In the study of Shin Yoon Kim, 38 the rate of conversion to total hip replacement was 13\% (three of 23 hips) in the vascularized graft group and $22 \%$ (five of 23 hips) in the nonvascularized graft group in comparison only three patients out of 68 of TFL muscle pedicle grafting was advised total hip replacement in the present series at the end of 16 years (Fig 6A-6F). The hips treated with TFL muscle pedicle
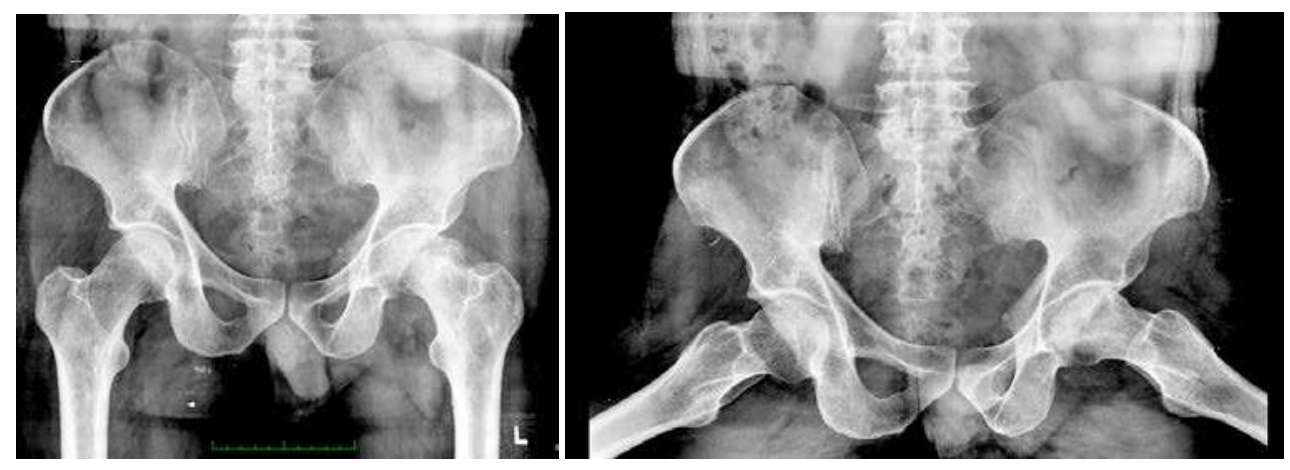

SR - 52 years

Fig. 6. 6A, 6B - X ray showing Alcohol induced ON femoral heads both sides Stage II - Right side, \& Stage - III left side in 52 years male

grafting seemed to have less dome depression of the femoral head and the retention of sphericity, probably because of more rapid revascularization and increased osteoinductive potential of the pedicle graft. It has been observed that there is an early failure of total hip replacement in osteonecrosis than in age-matched patients with other diagnosis because of abnormal remodeling of bones and subsidence of prosthesis because of poor quality of proximal femoral bone ${ }^{42}$. Other contributory factors for failure are ongoing systemic disease, defects in mineral metabolism, use of steroids, and high level of activity in young patients and increased body weight. Hence, we prefer to delay or eliminate the need for hip replacement by performing head-preserving surgeries ${ }^{10}, 37$, of which core decompression 
and TFL muscle pedicle grafting are a choice of surgery, especially in bilateral cases and patients with Sickle cell disease with stage II and III. Out of 68 patients, only five patients progressed to collapse, and surgery of joint replacement was advised in three patients.
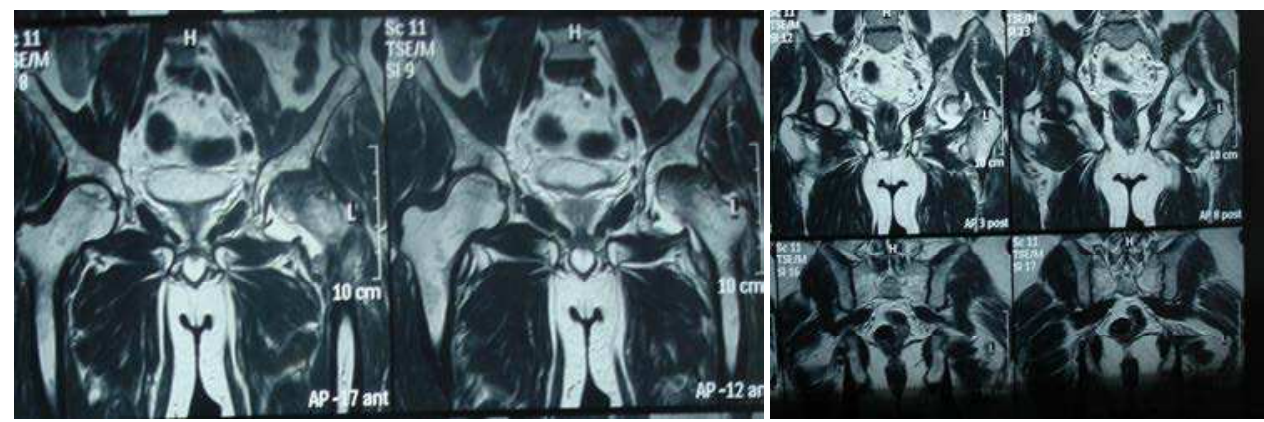

Fig. 6. 6C, 6D - MRI showing bilateral ON in 52 years male
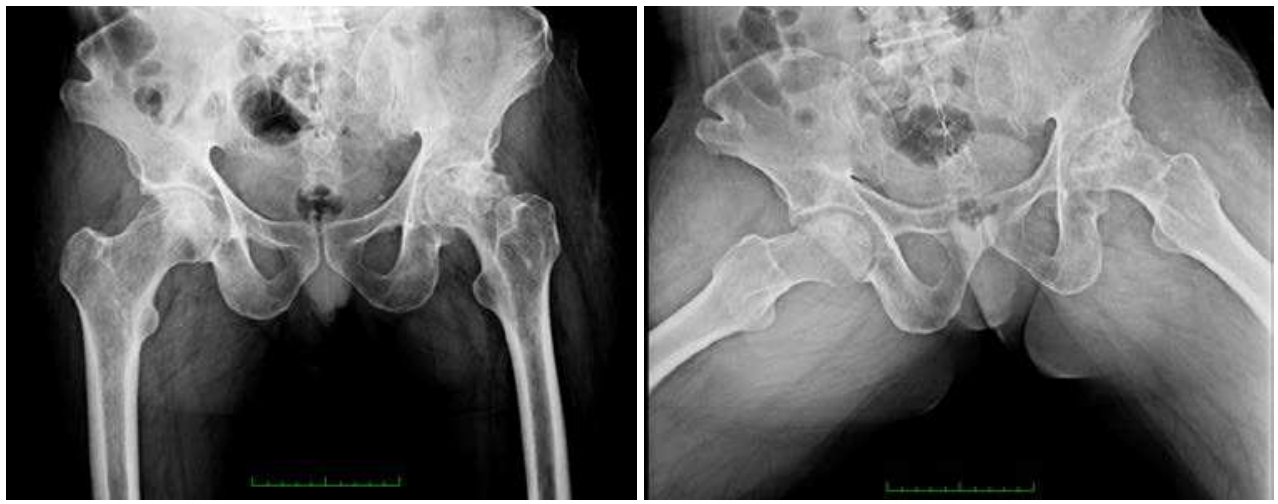

Fig. 6. 6E, 6F - PO 1 year $X$ ray showing collapse of femoral head with arthritic changes left side, good incorporation of graft right side with good joint space. Patient is advised THA left side

\section{Conclusion}

Basically osteonecrosis of femoral head is a multifactorial, heterogeneous group of disorder that leads to final common pathology of mechanical failure of femoral head. In this study more than seventy percent patients had osteonecrosis because of alcohol abuse $(42 \%) \&$ steroid consumption (30\%) and in 28 percent cases belonged to Sickle cell disease. It is common in young age group where conservative surgical approach is chosen, than a radical approach of reconstructive surgery. If diagnosed early head preserving operation of core decompression and TFL Muscle pedicle bone grafting yields excellent result. Essentially the result depends on the preoperative condition of the joint and the site of necrotic focus and the associated disease, which may be the cause of osteonecrosis. From our experience, if the 
ischemic necrosis of femoral head is diagnosed early in stage II, \& III core decompression and TFL Muscle pedicle grafting gives very good results. In stage III, even if there is slight collapse with deformation, the depressed segment can be elevated and deformity corrected after elevation and bone grafting. Out of 68 patients with 90 hips only five patients progressed to collapse and surgery of joint replacement was advised in three patients of stage III. The long standing effect of surgery were excellent with great improvement in the Harris hip score, achieving improvement in the score between $70-80$ points in majority of patients at the final follow up period.

\section{References}

[1] Glimcher MJ, Kenzora JE: The biology of osteonecrosis of the human femoral head and its clinical implications: Part III. Discussion of the etiology and genesis of the pathological sequelae; comments on treatment. Clin Orthop 1979; 140:273-312.

[2] Herndon JH, Aufranc OE: Avascular necrosis of the femoral heaad in the adult. A review of its incidence ina variety of conditions. Clin Orthop 1972; 86:43-62.

[3] Glimcher MJ, Kenzora JE: The biology of osteonecrosis of the human femoral head and its clinical implications: Part II. The pathological changes in the femoral head as an organ and in the hip joint. Clin Orthop 1979; 139:283-312.

[4] Kenzora JE, Glimcher MJ: Pathogenesis of idiopathic osteonecrosis: The ubiquitous crescent sign. Orthop Clin North Am 1985; 16:681-696.

[5] Mankin HJ: Nontraumatic necrosis of bone (osteonecrosis). N Eng J Med 1992; 326:14731479.

[6] Mont MA, Hungerford DS: Non-traumatic avascular necrosis of the femoral head. J Bone Joint Surg 1995; 77A: 459-474.

[7] Urbaniak JR, Coogan PG, Gunneson EB, et al: Treatment of osteonecrosis of the femoral head with free vascularised fibular grafting: A long term follow up study of one hundred and three hips. J Bone Joint Surg 1995; 77A: 681-694.

[8] Gardeniers JWM: ARCO international classification of osteonecrosis. ARCO News 1993; 5:79-82.

[9] Steinberg ME, Hayken GD, and Steinberg DR: A quantitative system for staging avascular necrosis. J Bone Joint Surg 1995; 77B: 34-41.

[10] Babhulkar SS: Osteonecrosis of femoral head: Treatment by core decompression and vascular pedicle grafting IJO - Vol 43 January Issue 1, March 2009: 27-35

[11] Meyers MH. The treatment of osteonecrosis of the hip with fresh osteochondral allografts and with the muscle-pediclegraft technique. Clini Orthop 1978; 130: 202209.

[12] Baksi DP. Treatment of osteonecrosis of the femoral head by drilling and musclepedicle bone grafting. J Bone Joint Surg (Br) 1991; 73-B: 241-245.

[13] Ficat P, Arlet J, Hungerford DS (eds): Ischaemia and Necrosis of Bone. Baltimore, MD, Williams \& Wilkins, 1980.

[14] Ficat RP: Idiopathic bone necrosis of the femoral head: Early diagnosis and treatment. J Bone Joint Surg 1985; 67B: 3-9.

[15] Boettcher WG, Bonfigilo M, Smith K: Non-traumatic necrosis of the femoral head: II. Experiences in treatment. J Bone Joint Surg 1970; 52A: 322-329. 
[16] Steinberg ME, Brighton CT, Hayken GD et al. Electrical stimulation in the treatment of Osteonecrosis of the femoral head - a 1 year follow-up. Orthop. Clin North Am 1985; 16: 747-756.

[17] Steinberg ME, Hayken GD, Steinberg DR. The conservative management of avascular necrosis of the femoral head. In Bone Circulation. Edited by Arlet A, Ficat RP, Hungerford DS. Baltimore; Williams and Wilkins. 1984: 334-337.

[18] Hungerford DS, Jones LC: Diagnosis of osteonecrosis of the femoral head. In Schoutens A, Arlet J , Gardeniers JWM, et al (eds): Bone Circulation and Vascularisation in Normal and Pathological Conditions. New York, NY, Plenum Press, 1993, pp 265275

[19] Steinberg ME, Hayken GD, and Steinberg DR: A quantitative system for staging avascular necrosis. J Bone Joint Surg 1995; 77B: 34-41.

[20] Arlet J, Ficat P: Forage-biopsie de la tete femorale dans l'osteonecrose primitive. Observations histo-pathologiques portant sur huit forgaes. Rev Rhumat 1964; 31:257-264.

[21] Bradway JK, Morrey BF: The natural history of the silent hip in bilateral atraumatic osteonecrosis. J Arthroplasty 1993; 8:383-387.

[22] Mitchell DG, Steinberg ME, Dalinka MK et al: Magnetic resonance imaging of the ischaemic hip: Alterations within the osteonecrotic, viable, and reactive zone. Clin Orthop 1989; 244:60-77

[23] Shimizu K, Moriya H, Akita T et al: Prediction of collapse with magnetic resonance imaging of avascular necrosis of the femoral head. J Bone Joint Surg 1994; 76A:215223.

[24] Beltran J, Knight CT, Zuelzer WA et al: Core decompression for avascular necrosis of the femoral head: Correlation between long-term results and preoperative MR staging. Radiology 1990; 175:533-536.

[25] Robinson HJ Jr: Success of core decompression in the management of early stages of avascular necrosis: A four-year prospective study. Proceedings of the American Academy of Orthopaedic Surgeons 59th Annual Meeting, Washington DC, Park Ridge, IL, American Academy of Orthopaedic Surgeons, 1992, p177.

[26] Norman A, Bullough P: The radiolucent crescent line: An early diagnostic sign of avascular necrosis of the femoral head. Bull Hosp Joint Dis 1963; 24:99-104

[27] Harris WH Tarumatic arthritis of the hip, J Bone Joint Surg(Am) 1969; 51A:738-743.

[28] Marcus ND, Enneking WF, Massam RA. The silent hip in idiopathic aseptic necrosis: treatment by bone grafting. J Bone Joint Surg (Am) 1973; 55-A: 1351-66.

[29] Kerboul M, Thomine J, Postel $\mathrm{M}$ et al: The conservative surgical treatment of idiopathic aseptic necrosis of the femoral head. J Bone Joint Surg 1974; 56B: 291-296.

[30] Steinberg ME, Brighton CT, Hayken GD et al. Electrical stimulation in the treatment of Osteonecrosis of the femoral head - a 1 year follow-up. Orthop. Clin North Am 1985; 16: 747-756.

[31] Steinberg ME, Hayken GD, Steinberg DR. The conservative management of avascular necrosis of the femoral head. In Bone Circulation. Edited by Arlet A, Ficat RP, Hungerford DS. Baltimore; Williams and Wilkins. 1984: 334-337.

[32] Ficat P, Arlet J, Hungerford DS (eds): Ischaemia and Necrosis of Bone. Baltimore, MD, Williams \& Wilkins, 1980. 
[33] Ficat RP: Idiopathic bone necrosis of the femoral head: Early diagnosis and treatment. $J$ Bone Joint Surg 1985; 67B:3-9.

[34] Jones JP Jr: Intravascular coagulation and osteonecrosis. Clin Orthop 1992; 277:41-53.

[35] Jones JP Jr Fat embolism, intravascular coagulation, and osteonecrosis Clin Orthop 1993 Jul;(292): 294-308

[36] Jones JP Jr: Concepts of etiology and early pathogenesis of osteonecrosis. In Schafer M (ed): Instructional Course Lectures 43. Rosemont, IL, American Academy of Orthopaedic Surgeons, 1994, pp 499-512

[37] Babhulkar SS :Osteonecrosis of the femoral head (in young individuals) Indian Journal of Orthopaedics Vol.37, No.2; April 2003:77-86

[38] Yoon S,Goo Y, Kim PT, Ihn JC, Cho BC, Koo KH. Vascularized compared with nonvascularized fibular grafts for large osteonecroic lesion of the femoral head. $J$ Bone Joint Surg Am 2005; 87:2012-8

[39] Dutton RO, Amstuz HC, Thomas BJ, Hedley AK Tharies surface replacement for osteonecrosis of femoral head J Bone Joint Surgery Am 1982; 64: 1225-1237

[40] Leung PC, Chow YY.:Reconstruction of proximal femoral defects with a vascularpedicled graft J Bone Joint Surg Br, Jan 1984; 66-B: 32 - 37

[41] Leung PC: Vascular bone grafts from iliac crest Microsurgical technique in Orthopaedics Pho Robert WH, Butterworths; 135-144

[42] Plakseychuk AY, Bogov AA, Plakseychuk YA: vascularised Iliac crest Graft in the treatment of aseptic necrosis of femoral head; Reconstructive Microsurgery Current Trends Proceedings $12^{\text {th }}$ Symposium International Society of Reconstructive Microsurgery, Singapore 1996: 85-87

[43] Plakseychuk AY, Kim SY, Park BC, Varitimidis SE, Rubash HE, Sotereanos DG: Vascularised compared with nonvascularised fibular bone grafting for the treatment of osteonecrosis of the femoral head. J Bone Joint Surgery (Am) 2003; 85:589-96.

[44] Iwata H, Torii S, Hasegawa $\mathrm{Y}$, Itoh $\mathrm{H}$ et a.: Indications and results of vascularised pedical iliac bone graft in avascular necrosis of femoral head. Clin Orthop, 295:281, 1993 


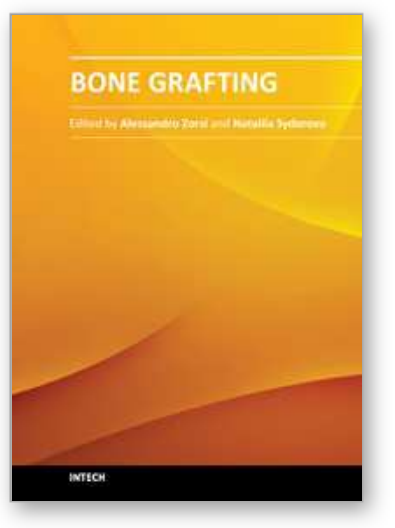

\author{
Bone Grafting \\ Edited by Dr Alessandro Zorzi
}

ISBN 978-953-51-0324-0

Hard cover, 214 pages

Publisher InTech

Published online 21, March, 2012

Published in print edition March, 2012

Bone grafting is the surgical procedure in which new bone (bone graft) or a replacement material (graft substitute), is placed into bone fractures or bone defects to aid in healing. Bone grafting is in the field of interest of many surgical specialties, such as: orthopedics, neurosurgery, dentistry, plastic surgery, head and neck surgery, otolaryngology and others. In common, all these specialties have to handle problems concerning the lack of bone tissue or impaired fracture healing. There is a myriad of surgical techniques nowadays involving some kind of bone graft or bone graft substitute. This book gathers authors from different continents, with different points of view and different experiences with bone grafting. Leading researchers of Asia, America and Europe have contributed as authors. In this book, the reader can find chapters from the ones on basic principles, devoted to students, to the ones on research results and description of new techniques, experts will find very beneficial.

\title{
How to reference
}

In order to correctly reference this scholarly work, feel free to copy and paste the following:

Sudhir Babhulkar (2012). Osteonecrosis Femoral Head Treatment by Core Decompression and ILIAC CRESTTFL Muscle Pedicle Grafting, Bone Grafting, Dr Alessandro Zorzi (Ed.), ISBN: 978-953-51-0324-0, InTech, Available from: http://www.intechopen.com/books/bone-grafting/osteonecrosis-femoral-head-treatment-bycore-decompression-and-iliac-crest-tfl-muscle-pedicle-grafti

\section{INTECH}

open science | open minds

\section{InTech Europe}

University Campus STeP Ri

Slavka Krautzeka 83/A

51000 Rijeka, Croatia

Phone: +385 (51) 770447

Fax: +385 (51) 686166

www.intechopen.com

\section{InTech China}

Unit 405, Office Block, Hotel Equatorial Shanghai

No.65, Yan An Road (West), Shanghai, 200040, China 中国上海市延安西路65号上海国际贵都大饭店办公楼405单元

Phone: +86-21-62489820

Fax: $+86-21-62489821$ 
(C) 2012 The Author(s). Licensee IntechOpen. This is an open access article distributed under the terms of the Creative Commons Attribution 3.0 License, which permits unrestricted use, distribution, and reproduction in any medium, provided the original work is properly cited. 